\title{
UTILIZATION OF INDUCTION HEATING TECHNOLOGY IN GALVANIZING LINES
}

\author{
Victor Demidovich ${ }^{1}$
}

\begin{abstract}
Continuous Hot-Dip Galvanizing lines are widely used for the production of coated steel sheets. Quality improvement measures are of great importance for this type of line. A significant proportion of production and quality losses when operating these types of lines occurs when production is transitioning from one strip gauge/thermal cycle to another. Utilizing induction heating technology, in combination with a sophisticated control system, can dramically decrease yield losses during transitions. Dynamic Transition and Production Planning Models have recently been developed for the simulation and control of the continuous hot-dip galvanizing line. The results of this work have been implemented in some galvanizing lines with production rate up to 350,000-ton annual capacity.
\end{abstract}

UDC Classification: 621.5, DOI: http://dx.doi.org/10.12955/cbup.v3.647

Keywords: hot-dip galvanizing, induction heating, transition model, production planning model

\section{Introduction}

Hot-Dip Galvanizing is a process in which an adherent, protective coating of zinc and zinc compounds is developed on the surface of iron and steel products by immersing them in a bath of molten zinc.

Galvanized steel strip is produced from low carbon steel, usually containing 0.05 to 0.10 percent carbon. The range can be expanded by two points in either direction with no significant consequences other than an increase in the range of mechanical properties exhibited by the product.

Steel for production of galvanized strip is brought to the heating equipment from the cold or hot rolling mill in a fully-hardened condition. It should be annealed to impart the necessary mechanical properties to meet the requirements for galvanized products. At an adequately high temperature, the metal structure fully recrystallizes into approximately equiaxed grains. Annealing of the steel coils could be realized in either continuous or batch operations.

Heating and cooling rates, which are important variables in some continuous annealing processes, are not significant in the production of galvanized steel. Heating and cooling equipment is most frequently selected on the basis of overall cost effectiveness, rather than space requirement, for instances, where plant space is an issue - usually without concern for the rate of heat transfer on the product.

Continuous annealing provides productivity where long runs and similar grades and strip sizes dominate the product mix. When dealing with many grades, strip sizes, and smaller orders, batch annealing makes sense because frequent change of heating cycles and dimensions of strip can bring about a 10-15\% loss of strip in scrap in the all modern continuous galvanizing line (Dubois \& Boyer, 1995). Implementation of induction heating in the continuous line can dramatically change the situation in favor of the continuous galvanizing line (Demidovitch, Nelson, \& Blake, 2000).

\section{Main objectives of utilizing induction heating}

The application of induction technology to continuous galvanizing lines achieves two operating objectives:

- Maximize quality by minimizing off-prime product

- Maximize productivity and profitability by minimizing under-utilization of equipment through transitions

Many other factors also influence the choice of induction heating in continuous galvanizing line, such as total length of installation, processing time, efficiency at full load and partial load, cost of final energy,

1 Victor Demidovich, professor, Sankt-Petersburg Electrotechnical University (LETI), Russia, vbdemidovich@mail.ru 
energy saving, $\mathrm{CO}_{2}$ emission, operator ease of use, potential for automation, etc. One of the earliest uses of transition induction heating in galvanizing lines is described by Delaunay (1996).

\section{Possible equipment and configuration of Continuous Galvanizing Lines}

Steel strip that is to be hot-dip galvanized after rolling must be free of oil, grease, drawing lubricant, mill scale, and other surface contaminants. If a high-performance cleaning method is chosen, then any type of heating can be adopted. Direct-fired furnaces (DFF), radiant tube furnaces (RTF) utilizing gas or electricity, and induction furnaces (IF) can be used. The combination of electrolytic cleaning with a radiant tube furnace has actually prevailed in high-capacity galvanizing lines (Suemutsi, 1995). In the case of an all-radiant-tube furnace, starting time and thermal response are longer than those of the directfired furnace and the induction furnace. Moreover, radiant tubes are maintenance-intensive.

An alternative approach can be used with a wide range of strip sizes and heating cycles. Direct-fired non-oxidizing furnaces are successfully used for combination cleaning and heating strip operations (Wang, 1991). In this case, the protective atmosphere radiant tube furnace is installed after the directfired furnace to complete the heating of the strip and ensure optimal strip surface conditions to provide correct zinc adhesion in the subsequent operation.

In both the all-radiant-tube and combination radiant-tube/direct-fired preheat cases, the implementation of induction heating technology allows an increased quality of the products and output capacity of the line.

The final design of induction furnaces is a function of one of the following goals:

- Using induction heating only for utilization of transitions in the line, connected with strip cycles and size changes.

- Using induction furnaces for heating and for transitions in combination with DFF for heating and cleaning.

- Using induction furnaces for heating and for transitions with separate cleaning devices.

Descriptions of the induction coils that can be used in galvanizing lines are presented by Demidovich, Rastvorova, \& Sitko (2014). The final design of induction coils is carried out with input received from thermal models, which simulate each stage of the strip heating process. These models were originally developed for the evaluation of heat transfer processes in the galvanizing line including evaluation of electromagnetic processes in the induction sections. The present stage of development has extended the models use to permit whole line design integration.

Figure 1 illustrates a typical temperature profile of the strip along the processing line for Commercial Quality (CQ) product up to the point of strip immersion in the zinc bath. The strip passes through the (1) Preheat Tunnel, (2) Direct Fired Furnace (DFF), (3) Induction Coil, two Radiant Tube Furnace (RTF) sections (4) and (5), wherein (4) is used for heating, and (5) is used for soaking before entering the convection Cooling Zone (6) where the strip temperature is reduced to that of the zinc pot for satisfactory coating. A preheat tunnel is an unfired section of the furnace system designed to preheat the strip utilizing the exhaust gases from the direct-fired furnace installed below in an L-shape line configuration. The temperature in the preheat tunnel is not directly controlled. The waste gases from the direct-fired section are exhausted through this section as the strip travels vertically. The strip travels from the preheat tunnel into the direct-fired furnace section where it is cleaned as it is being heated. The processing of the strip leads to oil evaporation, strip cleaning, and strip surface oxide reduction. The burners are fired in a sub-stoichiometric condition to reduce any oxide formation on the strip surface. The incorporation of an induction coil in the line ensures rapid transition times when changing strip parameters. 
Atmosphere radiant tube sections receive the strip from the induction coil and heat it to a maximum temperature of up to $900^{\circ} \mathrm{C}$ - depending on the heat treatment cycle. After the strip has undergone the correct heating and soaking cycle, it will pass through the modular convection cooling section, which will reduce the strip temperature to match the zinc pot temperature. This strip cooling is accomplished by recirculating hydrogen/nitrogen atmosphere through water-cooled heat exchangers and by impinging the cooled atmosphere gas on the strip surface using a high efficiency circulation concept.

Product quality, typically, depends on successfully executing this profile within certain limits even during transitions from different gauges and cycles of strip. It is a preferred practice to limit the temperature at the exit of the preheat tunnel (T1) to a maximum of $260^{\circ} \mathrm{C}$. Similarly, strip temperature exiting the direct-fired section (T2) should ideally be in the $538^{\circ} \mathrm{C}$ to $746^{\circ} \mathrm{C}$ range. For the CQ Cycle, the desired strip temperature (T4) is $732^{\circ} \mathrm{C}$. The minimum strip temperature could be $730^{\circ} \mathrm{C}$, and the maximum could be $760^{\circ} \mathrm{C}$. Temperature of the strip after convection cooling (T6) should be in the range of $465^{\circ} \mathrm{C}$ to $477^{\circ} \mathrm{C}$. Without proper transition management, substantial deviations from these temperatures are likely to occur, which will invariably lead to a loss of product quality (Demidovitch \& Goodlin, 2001).

\section{Utilizing Induction Coils in the Galvanizing Line}

In the case where production transitions from one gauge/treatment cycle to another, with the line speed remaining the same and with no other intervention, the incoming strip will either overheat (lighter

Figure 1: Temperature profile for CQ cycle - gauge $0.78 \mathrm{~mm}$, speed of strip $90 \mathrm{~m} / \mathrm{min}$

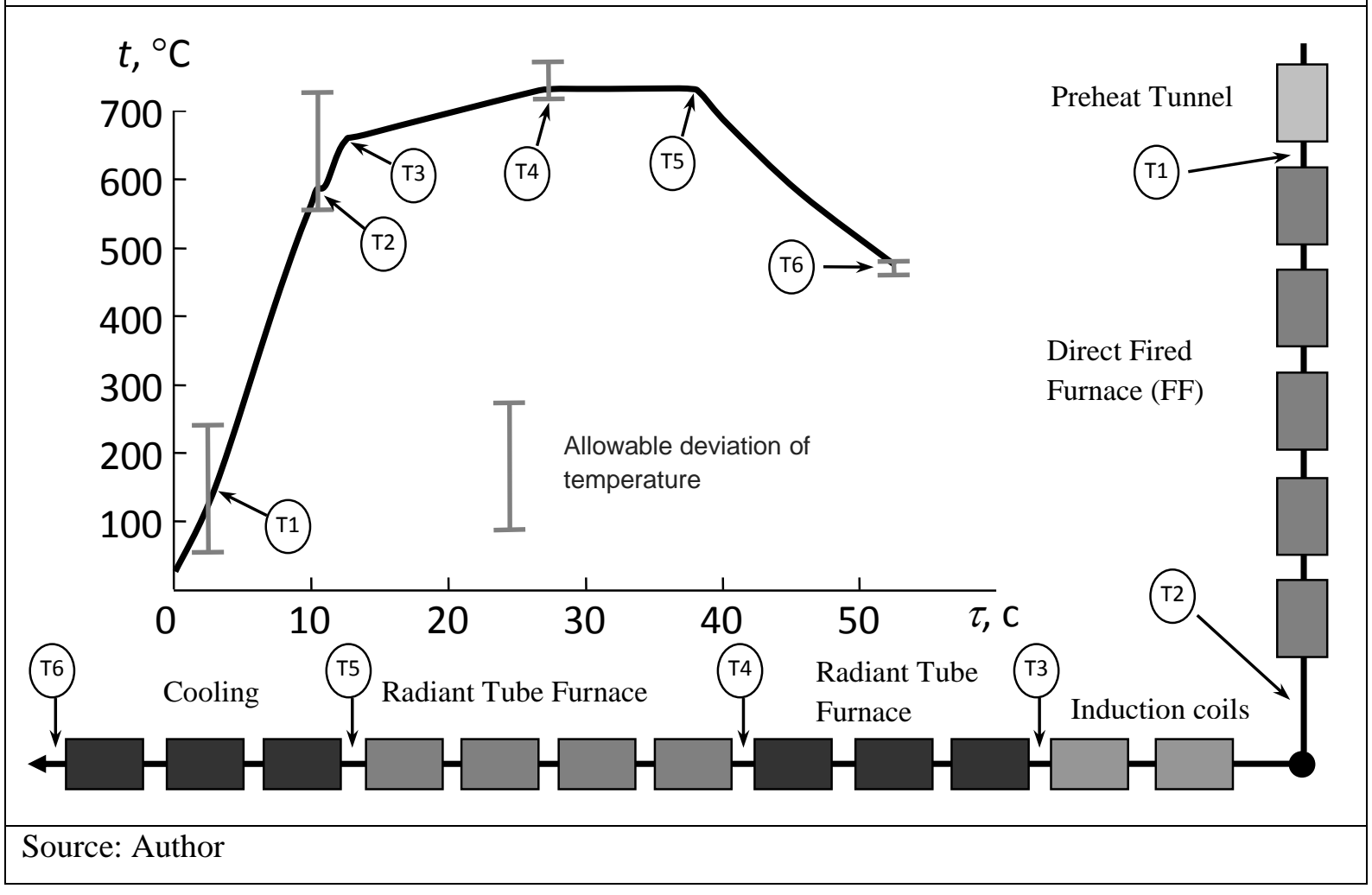

gauge entering) or underheat (heavier strip entering) until the line speed appropriate to this new gauge/treatment cycle is established. Under/overheating of the strip outside the established limits will result in product loss and will reduce overall line yield as noted above.

Implementation of induction heating supplements line speed as a means of intervention during transitions (Bill, 2005). The near-instant response of induction heating gives the practical ability to process different gauges of strip at the same line speed without the deviation in temperature at the exit 
of RTF (T4) throughout the transitioning process. This ability permits certain ranges of differing strip thicknesses to be run at the same line speed, which minimizes the need for changes in the air-knifes settings and, thus, eliminates another potential source of quality deviation within the product. Thus, this strategy can be expected to raise the overall yield rates from the line.

Figure 2 shows the temperature profiles of strip with different thicknesses travelling through the system at a constant speed. This figure illustrates the ability of the induction coils to boost the lagging temperature of a thicker strip by a sufficient margin, so that even with "underheating" in the DFF the actual process target temperature at the exit of RTF can be maintained. For economic reasons, it is usual to impose some restrictions on the power of inductors for any given system. It is usually economically practicable to limit "seamless" transitions (i.e. same speed transitions utilizing only changes in inductor power) to a $20 \%$ change in the gauge thickness.

Process restrictions on the temperature at the exit of DFF also place practical limits on the power of inductors. Using the thickest strip given in Figure 2, as an example, it would not guarantee a satisfactory product since the strip temperature at the exit DFF will be less than $538^{\circ} \mathrm{C}$, which is is outside the normal process constraints for effective strip surface preparation, even if additional induction power was available.

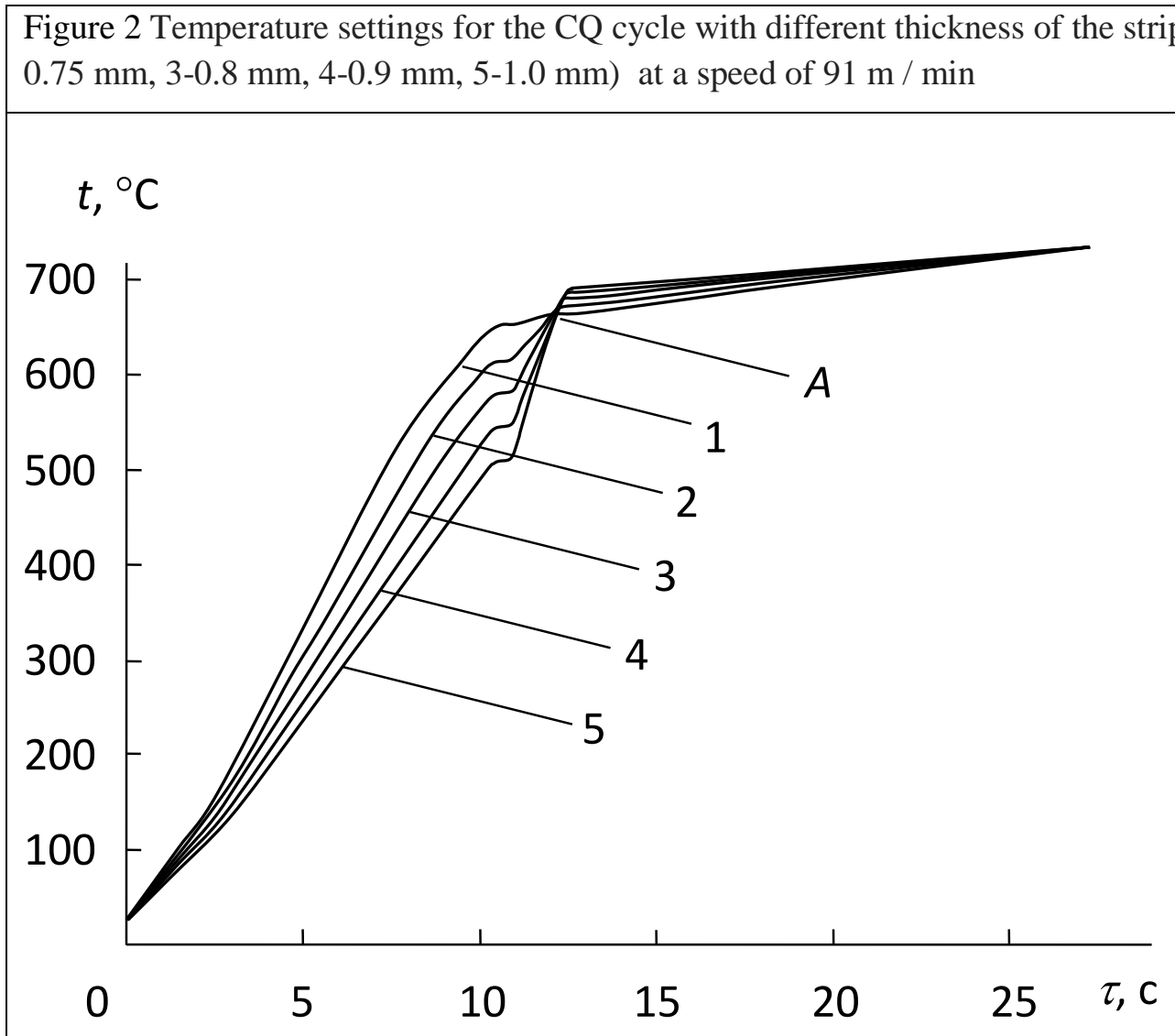

Source: Author

Another peculiarity of these transitions is that all curves cross at the one point A. The position and a temperature level of this point for each cycle remains constant irrespective of differences in strip thicknesses and corresponding line speed.

These data were obtained using a nonlinear model of temperature regime of heating tape (HTM). In the linear case, and assuming a uniform temperature across the width of the tape, the temperature at point 
A and its position inside the inductor (Figure 3) can be determined by simple formulae (Demidovitch, Blake, \& Churchill, 2001):

$$
\begin{gathered}
T_{s}=T_{0}+\frac{T_{f}-T_{0}}{\left[1+(c / a) \times\left(p_{a} / p_{c}\right)\right]}, \\
x=\frac{b}{\left[1+(c / a) \times\left(p_{a} / p_{c}\right)\right]},
\end{gathered}
$$

where:

$T_{0}$ - the temperature of the strip at the entrance; $T_{f}$ - exit temperature of the strip; a - active length of the Direct Fired Furnace (DFF); b - active length of inductors; c - active length of the (RTF);

$p_{a}$ - the average power density of DFF;

$p_{c}$ - the average power density of RTF.

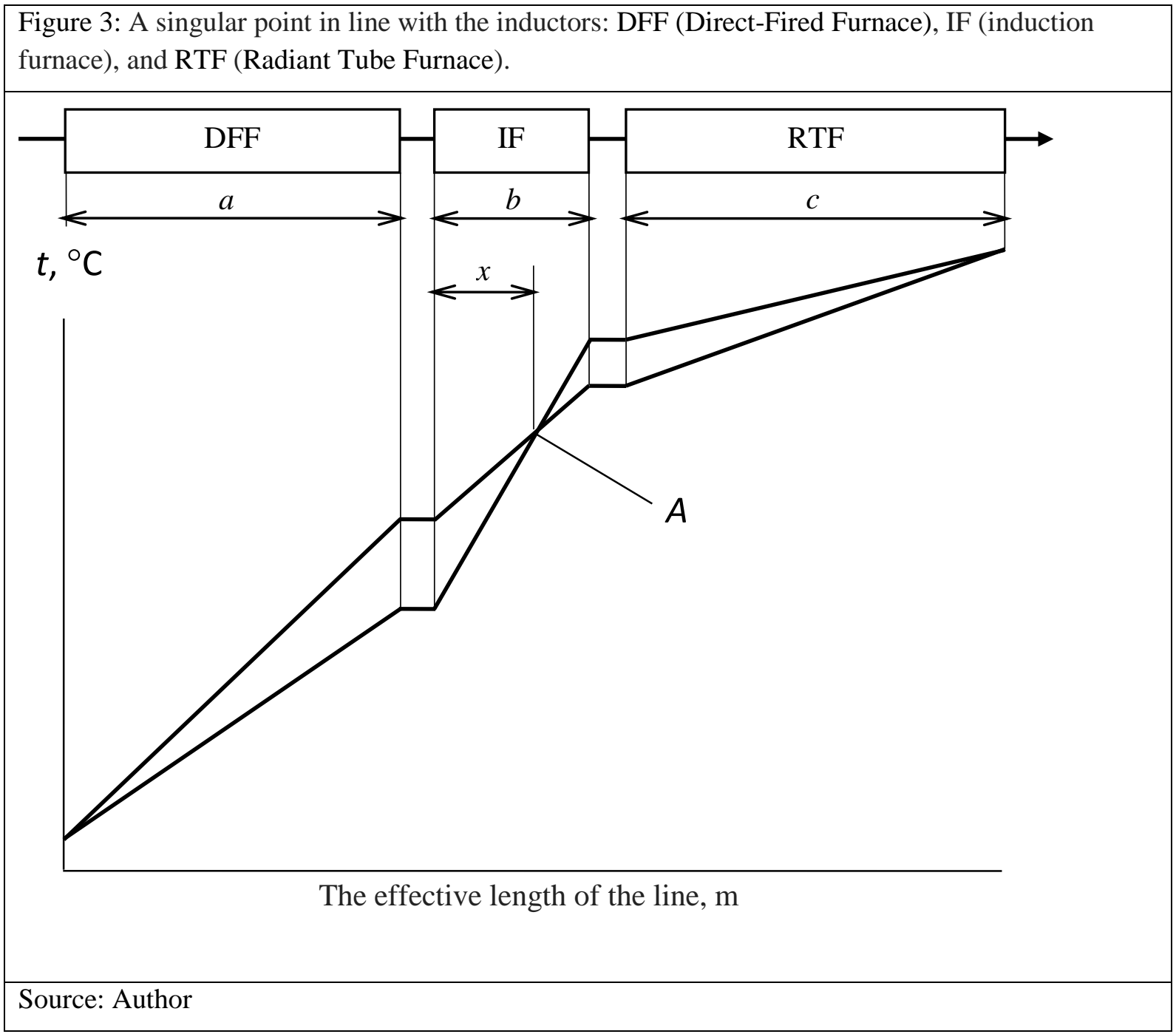

This peculiarity is utilized by a specially developed control system, Demidovitch et al. (2001), which can be used for "feasible" transitions, requiring only inductor power change or "deep" transitions, where both inductor power and speed changes are required to obtain a satisfactory outcome. A cascading 
control loop initially changes inductor power with final "trimming" of the line speed as required to maintain the known temperature at the point $\mathrm{A}$.

In operation, it is very useful to subdivide the total product mix into ranges within which "feasible" transitions can be realized and the number of "deep" transitions will be minimized. Avoiding frequent "deep" transitions, especially between cycles, will dramatically decrease yield losses due to product quality. This underlines the importance of scheduling the coils treatment sequence.

A Production Planning Model (PPM) has also been developed to assist users in the scheduling of the heat treatment of stock coils. Once coil data have been entered into the system, the model predicts optimal coil sequencing to maximize quality by minimizing off-prime product and to maximize the productivity of the line. This model also predicts the ideal process speed for the strip and the necessary power of the inductors.

\section{Dynamic Transition Model}

The Hot-dip Galvanizing Line is a complex system of many aggregates with distributed parameters and a significant thermal inertia. Results of the transitions depend on the algorithms in which the control system utilizes. The Dynamic Transition Model (DTM) has been developed to evaluate the strip temperature disturbance in each point of the line during transitions from one coil to another and/or one cycle to another. The main control actions in this line are the strip speed and the power of inductors. All dynamic characteristics of the driving system and technological aggregates are also taken into account.

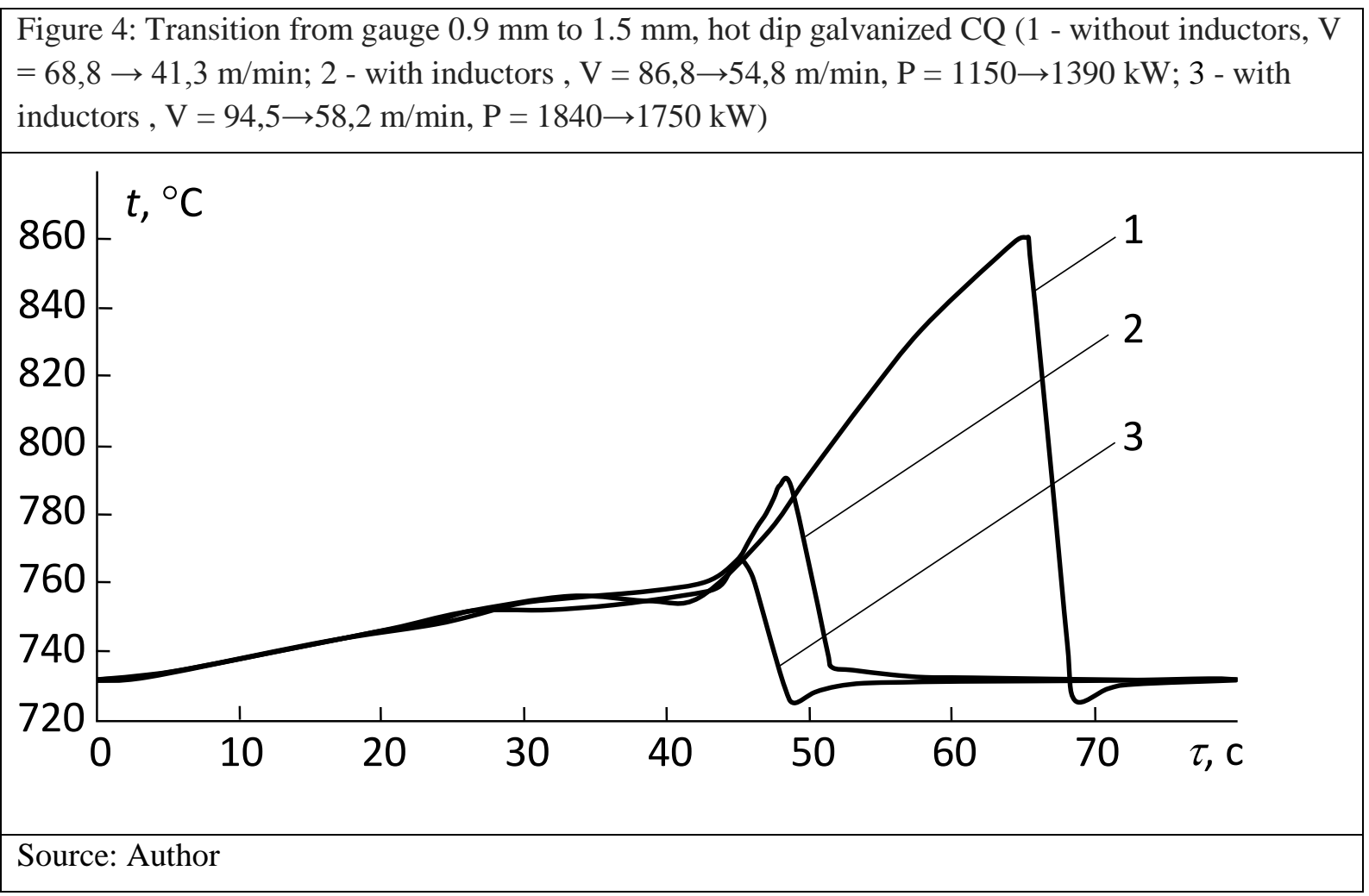

When transitions from one cycle to another occur, it is necessary to change the mode of Radiant Tube Furnace operation. The advantage of using induction heating coils during deep transitions is shown in Figure 4. The strip temperature deviates at the exit of RTF (T4) from the target temperature of $732^{\circ} \mathrm{C}$ (CQ cycle) during transition from gauge $0.9 \mathrm{~mm}$ to $1.5 \mathrm{~mm}$. Without inductors, the target temperature could be reached for a strip gauge of $0.9 \mathrm{~mm}$ at the speed of $68.8 \mathrm{~m} / \mathrm{min}$ and for the heavier strip with gauge of $1.5 \mathrm{~mm}$ at the speed of $41.3 \mathrm{~m} / \mathrm{min}$. Using the additional heating capabilities that the induction coils permits, the line may be run at higher speeds - for gauge of $0.9 \mathrm{~mm}$ at the speed $86,8 \mathrm{~m} / \mathrm{min}$ and 
for gauge of $1.5 \mathrm{~mm}$ at the speed $54,8 \mathrm{~m} / \mathrm{min}$. This essentially allows decreasing fluctuation of the strip temperature during transitions. Additionally, deep change of inductor power improves temperature curve during transitions.

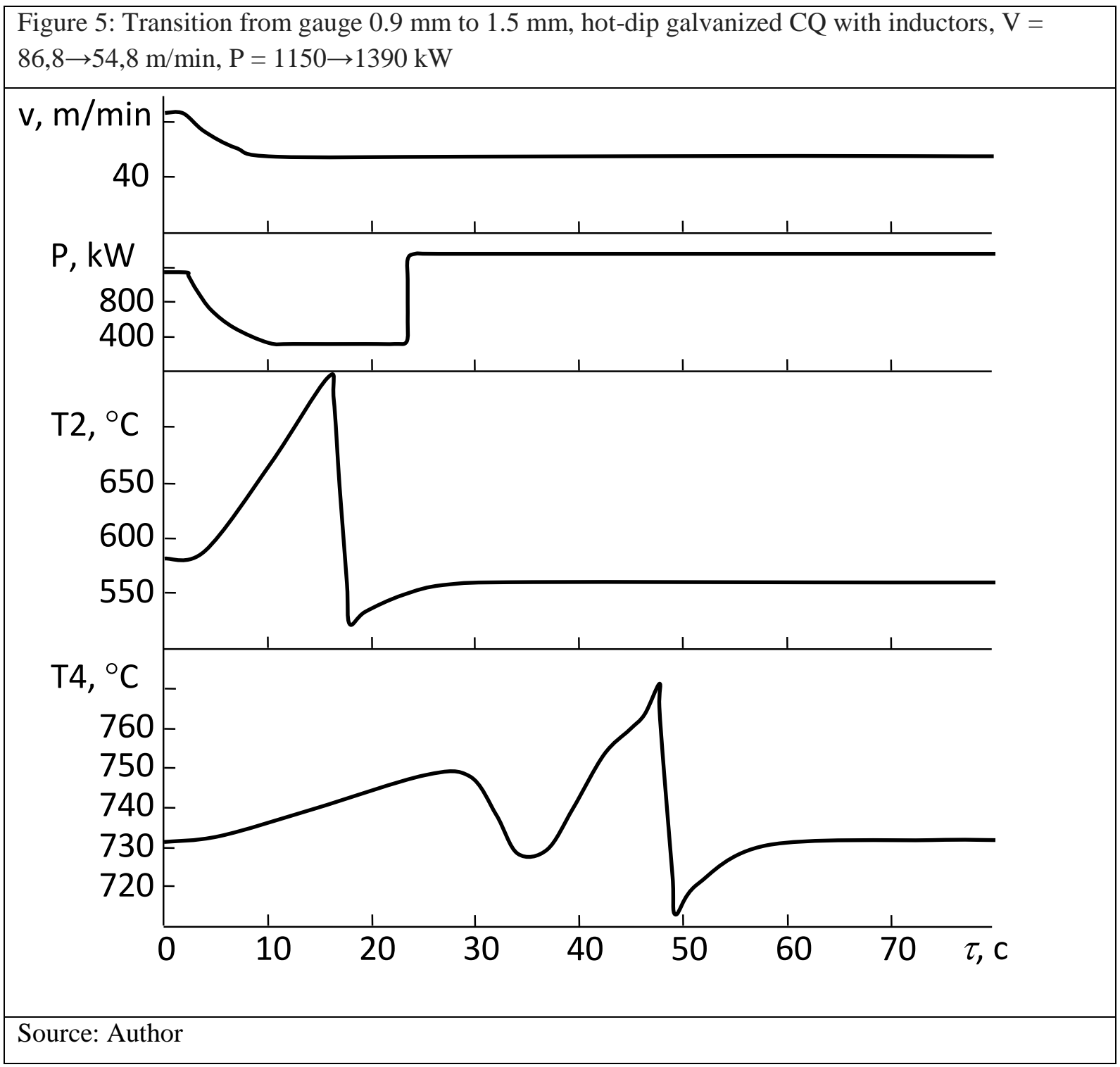

In certain instances, acceptable results of "deep" transitions could be performed with simpler algorithms. As an example, if the incoming strip is thicker, speed begins to change when the welding point is at the entrance of the pre-heater with inductor power changes being initiated when the welding point is in the inductors. Conversely, if the incoming strip is thinner, speed and inductor power begins to change when the welding point is in the inductors. Figure 5 shows an example of a transition. Since the position of the welding point is a trigger for transitions, its position needs to be accurately determined to ensure optimal results from this control methodology.

\section{Conclusion}

The utilizing of induction heating in continuous galvanizing lines, when coupled with sophisticated control systems, has the potential to improve the overall line yield by minimizing product losses during transitions. The Dynamic Transition Model (DTM) and Production Planning Model (PPM) have been developed to evaluate the strip temperature disturbance in each point of the line during transitions from one coil to another and/or one cycle to another and to assist users in the scheduling of the heat treatment 
CBU INTERNATIONAL CONFERENCE ON INNOVATION, TECHNOLOGY TRANSFER AND EDUCATION

of stock coils. The results of this work have been implemented in some galvanizing lines with production rate up to 350,000-ton annual capacity.

\section{References}

Bill, R. (2005). Overview of Coating Pots and Induction Strip Heaters in Today's Galvanizing Lines. AISTech Proceedings, 2.

Delaunay, D. (1996). UIE XIII Congress on Electricity Applications. MIII.

Demidovitch, V., Blake, E., \& Churchill, R. (2001, July). Single-Point Temperature Control System for a Multi-Section Line Furnace. United States Patent № 6,259071.

Demidovitch, V., \& Goodlin, W. (2001). A Furnace with Multiple Electric Induction Heating Sections Particularly for Use in Galvanizing Line. United States Patent № 6,180,933.

Demidovitch, V., Nelson, J., \& Blake, E. (2000) New Generation of Galvanizing Lines Utilizing Induction Heating Technology. $3^{\text {rd }}$ International Symposium on Electromagnetic Processing of Materials, Nagoya (Japan), 224-229

Demidovich, V. B., Rastvorova, I. I., \& Sitko, P. A. (2014). Advanced induction heating of thin plate products. Acta Technica, 3, 291-301.

Dubois, P., \& Boyer, M. (1995). GALVATECH'95. Chicago.

Suemutsi, Y. (1995). GALVATECH'95, 3. Chicago.

Wang, R. (1991). MPT-Metallugical Plant and Technology International, 4, 126. 